\title{
Genetic Admixture and Gallbladder Disease in Mexican Americans
}

MARILYN TSENG,,$_{1}$ ROBERT C. WILLIAMS,,$_{2}$ KURT R. MAURER,,$_{3}$ MOSES S. SCHANFIELD, 4 WILLIAM C. KNOWLER, 5 AND JAMES E. EVERHART 6

1. Department of Epidemiology and Center for Gastrointestinal Biology and Disease, University of North Carolina at Chapel Hill, Chapel Hill, North Carolina 27599

2. Department of Anthropology, Arizona State University, Tempe, Arizona 85287

3. National Center for Health Statistics, Hyattsville, Maryland 20782

4. Analytical Genetic Testing Center, Inc., Denver, Colorado 80231

5. National Institute of Diabetes and Digestive and Kidney Diseases, Phoenix, Arizona 85014

6. National Institute of Diabetes and Digestive and Kidney Diseases, Bethesda, Maryland 20892

ABSTRACT Gallbladder disease is a common source of morbidity in the Mexican American population. Genetic heritage has been proposed as a possible contributor, but evidence for this is limited. Because gallbladder disease has been associated with Native American heritage, genetic admixture may serve as a useful proxy for genetic susceptibility to the disease in epidemiologic studies. The objective of our study was to examine thepossibility that gallbladder disease is associated with greater Native American admixture in Mexican Americans. This study used data from the Hispanic Health and Nutrition Examination Survey and was based on 1,145 Mexican Americans who underwent gallbladder ultrasonography and provided usable phenotypic information. We used the GM and KM immunoglobulin antigen system to generate estimates of admixture proportions and compared these for individuals with and without gallbladder disease. Overall, the proportionate genetic contributions from European, Native American, and African ancestries in our sample were $0.575,0.390$, and 0.035 , respectively. Admixture proportions did not differ between cases and noncases: Estimates of Native American admixture for the two groups were 0.359 and 0.396 , respectively, but confidence intervals for estimates overlapped. This study found no evidence for the hypothesis that greater Native American admixture proportion is associated with higher prevalence of gallbladder disease in Mexican Americans. Reasons for the finding that Native American admixture proportions did not differ between cases and noncases are discussed. Improving our understanding of the measurement, use, and limitations of genetic admixture may increase its usefulness as an epidemiologic tool as well as its potential for contributing to our understanding of disease distributions across populations.

Gallbladder disease is a common source of morbidity in the Mexican American population. An estimated 17\% of Mexican Americans between the ages of 20 years and 74 years have gallstones or have had surgery for gallstones, in contrast to only $8-10 \%$ of non-Hispanic whites and African Americans (Khare et al., 1995). Differences in genetic predisposition may be an important 
determinant of risk, but relatively little is known about the causes of the disease, and what produces the high prevalence observed in Mexican Americans remains largely speculative.

The most consistent evidence for a genetic basis for gallbladder disease comes from the observed differences in prevalence across populations-differences that are not explained readily by any known environmental risk factors, including obesity, parity, oral contraceptive use, and diet (van der Linden, 1980). Evidence for a genetic basis is especially strong for Native Americans and their related groups, for some of whom prevalence has been estimated to be as high as $50 \%$ (Sampliner et al., 1970). Not only does prevalence of gallbladder disease appear to be high in Native American groups throughout the Americas (Diehl, 1991; Weiss et al., 1984), but the distribution of the disease is consistent with the distribution of Native American genes: Prevalence is lowest in whites and African Americans, it is highest in Native Americans, but it is intermediate in admixed populations, such as Mexican Americans (Hanis et al., 1986). The observation that the pattern of disease distribution seems to follow the pattern of Native American gene distribution provides further support for the possibility of a genetic basis to the disease in Native and Mexican Americans.

In most previous studies on the genetic epidemiology of gallstones, family history of the disease has been taken to represent genetic susceptibility (Gilat et al., 1983; Hanis et al., 1985; Jorgensen, 1988; Rome Group for Epidemiology and Prevention of Cholelithiasis, 1988; van der Linden and Lindelof, 1965; van der Linden and Simonson, 1973; Wheeler et al., 1970). These studies have found fairly consistently that there is some association between family history and gallstones.

Because gallstones have been associated with ethnic background, genetic admixture can also be used as a proxy for genetic susceptibility to the disease. In populations with high prevalence of gallstones, in fact, admixture may be more useful than family history in detecting an association between genetic susceptibility and gallbladder disease: The use of family history to seek evidence of familial aggregation may prove futile if the genes of interest are already present in most of the population (Knowler et al., 1984).

Genetic admixture has been measured in several epidemiologic studies in Native and MexicanAmerican populations (Chakraborty et al., 1986; Gardner et al., 1984; Knowler et al., 1988; Stern et al., 1992), generally with the objective of showing that greater Native American admixture is associated with diabetes, gallstones, or obesity-health outcomes that together form a constellation of diseases called the "New World Syndrome" (Weiss et al., 1984). In the three studies that have specifically examined the relationship between Native American admixture and gallbladder disease, a variety of techniques have been used to measure admixture, including skin 
reflectance, reported ancestry, and genetic markers (Hanis et al., 1986; Knowler et al., 1984; Mitchell et al., 1993). Although all three found higher prevalence of gallbladder disease in subjects with the most Amerindian heritage, none could demonstrate any clear and consistent trend of increasing prevalence with increasing Amerindian heritage.

Another method of measuring admixture makes use of the GM and KM immunoglobulin antigen system. GM allotypes are found on the $\Upsilon$ heavy chain of immunoglobulin G $(\operatorname{IgG})$, specifically, subclasses IgG1 and IgG3, whereas KM allotypes are found on the $\Upsilon$ light chain of Ig. The highly polymorphic GM system has been used successfully in previous admixture studies, because the differences in parental frequencies for some haplotypes are large (Knowler et al., 1988; Long et al., 1991), thus yielding more precise estimates of admixture (Williams, 1994). Although the frequency of haplotype $G M^{*} F B 0,1,3,4,5$ is as high as $67 \%$ in the Caucasian population, for example, it is virtually nonexistent in Native Americans (Williams et al., 1985). For this reason, the GM immunoglobulin system is perhaps among the most powerful for deriving accurate estimates of genetic admixture.

We used data from the Hispanic Health and Nutrition Examination Survey (HHANES) to address the hypothesis that greater Native American admixture is associated with higher prevalence of gallbladder disease among Mexican Americans. The objective of our study was twofold: 1) to use GM and KM systems to measure genetic admixture proportions of Mexican Americans who participated in the HHANES and 2) to compare admixture proportions of Mexican Americans with and without gallbladder disease.

\section{MATERIALS AND METHODS}

\section{Study population}

The data used for this study are from the HHANES, a cross-sectional survey that was designed to assess the health status of the Hispanic American population in the United States. The design and sampling procedures used in the HHANES have been described in detail (National Center for Health Statistics, 1985). Briefly, the survey followed a four-stage sampling scheme that was designed to represent the civilian, noninstitutionalized, Hispanic population in the United States over the age of 6 months. Mexican Americans were selected from populations residing in Texas, New Mexico, Arizona, Colorado, and California. The survey period lasted from 1982 to 1984. Data collection methods included personal interviews, physical examinations and anthropometric measurements, and various diagnostic tests and laboratory analyses. Personal interviews were conducted at home by trained interviewers in either English or Spanish. Study participants were then asked to schedule appointments at a Mobile Examination Center, where they underwent a 
physical examination, a diet and health interview, and various diagnostic tests. A random halfsample of individuals between the ages of 20 years and 74 years was also invited to receive a gallbladder ultrasound. Of 2,360 Mexican Americans invited, 1,388 (59\%) ultimately received the ultrasound and provided usable results.

Cases were defined as subjects who had gallstones or who had had their gallbladders surgically removed, as indicated by ultrasound. Gallstones were diagnosed according to standard criteria by using real-time ultrasonography administered by health technicians trained in ultrasonography of the gallbladder region. Details of the diagnostic methods have been published previously (Maurer et al., 1989).

\section{Measurement of genetic admixture}

Ig allotyping for GM, AM, and KM markers was performed, as described previously (Schanfield and Fudenberg, 1975; Schanfield and Polensky, 1975), by using the reagents listed in Table 1. Of 1,388 individuals with usable ultrasound results, 1,146 were typed for GM allotypes, and 1,127 were typed for the KM locus.

Haplotype frequencies for the GM locus were estimated by an iterative maximum likelihood method that employed a likelihood function with 18 phenotypes and 6 haplotypes (Li, 1976). Variances for the haplotype frequencies were taken from the variance-covariance matrix. The variancecovariance matrix is the inverse of the information matrix and was also constructed by using the method of Li (1976). Frequencies for the KM locus were calculated by using the square-root method.

Pooled estimates of genetic admixture were based on eight markers - six at the GM locus and two at the KM locus. These admixture estimates were calculated by an iterative weighted, leastsquares method that was first suggested by Elston (1971) and later modified by Long and Smouse (1983). The method requires that the parental populations and the hybrid be well characterized at a set of genetic loci. After one allele is dropped from each locus, the remaining marker frequencies for all loci for parental and hybrid populations are incorporated into the appropriate matrices for the analysis. The method is a weighted procedure, because a variance-covariance matrix of hybrid allele frequencies, which is constructed from the parental frequencies and the estimates of admixture for the current iteration, is used as a weight in the least-squares algorithm. Detailed descriptions for performing the iterative weighted, least-squares calculation of the proportions of genetic admixture and their variances have been published and were followed in the present 
analysis of the association of genetic admixture and gallstone disease (Long and Smouse, 1983; Long, 1991).

Allele frequencies for the three parental populations, European, Native American, and African, were taken from published reports (Steinberg and Cook, 1981; Williams et al., 1985). Each haplotype frequency represents a weighted average in which the sample sizes are the weights. For the African parental group, a second weight was used that reflected the proportion of persons who originated from a particular geographical region in Africa from which the sample was drawn. Details of these weights and the studies included in the parental frequencies as well as maximum likelihood and weighted, least-squares models are available from the authors (R.C.W.).

\section{Other risk-factor information}

Age, sex, body mass index (BMI), acculturation, and diabetes were examined as potential confounders of the relationship between gallbladder disease and genetic admixture. Information on age, sex, and level of acculturation was gathered during interviews that were conducted at subjects' homes. Ages were dichotomized into two groups, with ages ranging from 20 to 39 years and from 40 to 74 years.

An acculturation score was computed for each subject based on responses computed for the following eight questions: 1) What language do you speak? 2) What language do you prefer? 3) What language do you read better? 4) What language do you write better? 5) What ethnic identification do you use? 6) What ethnic identification does/did your mother use? 7) What ethnic identification does/did your father use? 8) Where were you born? Your mother? Your father? Responses to questions 1 through 7 were on a scale from 1 to 5 , with 1 representing the strongest Mexican orientation and 5 representing the strongest American orientation. Question 8 could take values of 1,2 , or 4 , where 1 represented first generational status, 2 represented second generational status, and 4 represented third generational status or higher. Acculturation scores were calculated as the arithmetic mean of scores on the eight variables and were then categorized into tertiles. For persons who could not read or write, missing values for responses to the reading and/or writing questions were assigned the mean of the remaining, non-missing responses in order to compute the acculturation score. Acculturation scores were not calculated for $2.6 \%$ of all Mexican American participants 20-74 years of age who were missing responses to any of the other questions.

Subjects were weighed and measured during physical examinations at Mobile Examination Centers, and BMI was calculated for each subject as weight in kilograms per squared height in 
meters as an index of obesity. BMI was then categorized by using NHANES II criteria for overweight as a cut-off (Najar and Rowland, 1987): Overweight individuals were defined as men with BMI greater than $27.8 \mathrm{~kg} /{ }^{2}$, or women with BMI greater than $27.3 \mathrm{~kg} / \mathrm{m}^{2}$.

Oral glucose-tolerance tests were also administered at Mobile Examination Centers to subjects who had fasted overnight for 10-16 hours; following procedures recommended by the National Diabetes Data Group (1979), fasting blood samples were drawn, a 75-gram glucose load was administered, and additional blood samples were collected 1 hour and 2 hours later for blood glucose measurement. Individuals were defined as having diabetes according to World Health Organization criteria (1985) or if they reported being told by a doctor that they were diabetic.

\section{Statistical analysis}

Admixture estimates were compared between those with and without gallbladder disease. Differences in admixture proportions were tested by comparing 95\% confidence intervals of the point estimates. Two proportions were considered different at the $\alpha=0.05$ level of significance if their respective confidence intervals did not overlap.

The possibility that the association between admixture and gallbladder disease could be confounded by age, sex, BMI, acculturation, and diabetes was evaluated by examining their relationships separately with admixture and disease. Associations between these variables and gallbladder disease were assessed by comparing means and distributions of these variables between those with and without the disease. Admixture estimates and 95\% confidence intervals were compared across levels of each covariate in order to evaluate the association of each with admixture. Variables were considered confounders if they were found to be strongly associated with both disease and admixture.

All analyses were conducted for the sample without the use of sample weights. However, when weights were applied to the GM distribution, estimated haplotype frequencies did not differ, suggesting that selection into the sample was independent of GM phenotype and that results from weighted and unweighted sample data are unlikely to differ.

\section{RESULTS}

Among the 1,146 persons typed for GM allotypes who also had ultrasound of the gallbladder, the most frequent phenotype in the sample was GM A,F B0,G ( $n=360$ ), with the presumed genotype $G M^{*} A G /^{*} F B 0,1,3$ (Table 2). Also occurring with high frequency were phenotypes GM A G ( $n=268)$, GMFB0( $n=162)$, and GM A,F,X B0,G $(n=110)$. Twelve GM phenotypes 
among 26 persons were ambiguous and did not fit the standard genetic model that was employed in this analysis (Table 3). These phenotypes yield allotype linkage groups that are atypical and rare in the three parental populations for Mexican Americans. Of the 1,127 persons typed for the KM locus, 412 were positive for the $K M^{*} 1$ allotype, whereas 715 were not (Table 4).

The GM phenotype distribution in Table 2 was consistent with a genetic model that included 6 haplotypes and 21 genotypes. The haplotypes are 1) $\left.\left.\left.{ }^{*} A G ; 2\right){ }^{*} A, X G ; 3\right){ }^{*} A B 0,1,3 ; 4\right){ }^{*} A$ $B 0,3, T ; 5) * A B 0,1, C 5$; and 6) ${ }^{*} F B 0,1,3$. Their frequencies as well as the haplotype frequencies for the parental populations and the frequencies for the KM alleles for all groups are found in Table 5. In the HHANES Mexican Americans, the highest frequency haplotype is ${ }^{*} A G(0.463)$ followed by ${ }^{*} F$ $B 0,1,3(0.378)$ and $* A, X G(0.103)$.

A total of 1,145 Mexican Americans with ultrasonography results and either nonatypical GM or KM phenotypic information were included in analyses on the association between gallbladder disease and admixture. Gallbladder disease was present in 156 patients, or 13.6\% of the sample. Of these, 85 were found to have gallstones at time of ultrasound, and the remaining 71 had had previous cholecystectomy. Sociodemographic characteristics of the sample are shown in Table 6. Gallbladder disease patients, on average, were older and more overweight and included significantly higher proportions of women and persons with diabetes compared with noncases. The two groups were similar with respect to degree of acculturation.

Mean population admixture was estimated based on the markers shown in Table 5. Estimates of admixture proportions for the entire study population and for cases and noncases separately are shown inTable 7. Proportions of genetic contribution from European, Native American, and African ancestry in the study population were $0.575,0.390$, and 0.035 , respectively. Admixture proportions did not differ between cases and noncases. Gallbladder disease cases showed slightly lower proportions of Native American admixture and slightly greater proportions of European and African admixture The estimate of Native American admixture was 0.359 for cases and 0.396 for noncases, for a difference of only 0.037. However, confidence intervals for all estimates overlapped between the two groups. Estimated admixture proportions were also similar across levels of all other covariates of interest, including those that showed strong associations with gallbladder disease (Table 8).

\section{DISCUSSION}

This study found that proportionate genetic contributions to this Mexican American sample were $0.575,0.390$, and 0.035 from European, Native American, and African ancestries, respectively. 
There was no difference in mean population admixture proportions between cases with gallbladder disease and noncases. These results do not provide support for the hypothesis that greater Native American admixture is associated with greater prevalence of gallbladder disease. Admixture was also unrelated to being overweight, to diabetes status, and to level of acculturation in this population.

Although our study failed to find evidence of association between gallbladder disease and Native American admixture as a proxy for genetic susceptibility, these results cannot eliminate the possibility that gallblad der disease is genetically mediated or that susceptibility differences contribute to differences in prevalence across populations. It is possible that no genetic difference could be detected between those with and without gallbladder disease because of the decay of genetic disequilibria over time; with random mating over several generations, admixture and susceptibility genes may have become distributed more uniformly in the Mexican American population, such that, over time, one has ceased to be a good proxy for the other. In addition, because participants were identified through self-reported ethnicity, the Mexican Americans in the HHANES sample may not be representative of the larger population; possibly, those with more European admixture were less likely to report themselves as Mexican American, resulting in a biased selection of study participants. The lack of a detectable difference in admixture may also be due to uniformly high exposure to nongenetic factors that increase risk regardless of genotype, such as low intake of fiber. Indeed, it should be emphasized that, regardless of the role of genetic susceptibility in gallstone occurrence, nongenetic factors cannot be ignored as major determinants of the disease.

Three previous studies have examined the relationship between Native American genetic admixture and gallbladder disease. All measured individual-level rather than population-level admixture. In a study that was conducted in the Pima Indian population, Knowler et al. (1984) found higher prevalences of clinically diagnosed gallbladder disease in individuals reporting greater proportions of Native American ancestry, although there was no consistent increase in prevalence with increasing proportion of Native American heritage. Hanis et al. (1986), by using 16 polymorphic genetic markers to measure individual admixture in a population of Mexican Americans, found a near-significant trend of higher prevalence of gallbladder disease with greater proportion of Native American alleles only among women 15-44 years of age; however, there was no apparent shift in the distribution of individual admixture estimates toward greater Native American admixture. In another study on Mexican Americans, Mitchell et al. (1993) measured admixture based on reported ancestry, skin reflectance, and 18 polymorphic genetic markers and 
found that only in women did those with the greatest Native American admixture have higher gallbladder disease prevalence consistently across all three measures of admixture.

Although the findings of the three studies are suggestive of an association of gallstones with Native American admixture, the numbers of individuals at certain levels of admixture are small in two of the studies (Hanis et al., 1986; Knowler et al., 1984), making prevalence estimates at those levels somewhat unstable. Furthermore, in none of these studies were subjects systematically examined by cholecystography or ultrasonography; thus, persons with asymptomatic gallstones were not ascertained. In contrast, in the HHANES over half of the gallbladder disease cases had asymptomatic gallstones.

Measurement of individual-level admixture may also have been imprecise, especially in the Mexican American populations. Although reported ancestry has been shown by Williams et al. (1986) to be highly correlated with admixture estimates in Native American populations, its usefulness in Mexican American populations may be more limited, because admixture in the Mexican American population probably occurred in the distant past and was followed by many generations of random mating: Thus, reported ancestry based on number of Mexican-origin grandparents (Mitchell et al., 1993) may not reflect the degree of Native American heritage or, accordingly, genetic susceptibility. Admixture estimates for individuals based on genetic markers are also of limited usefulness unless data on a large number of informative loci are available (Hanis et al., 1986; Williams, 1994).

In these analyses, information from the HHANES also allowed for assessment of potential confounding by other factors, including age, sex, overweight, diabetes, and level of acculturation. Although several of these factors were associated with gallbladder disease, none appeared to be related to admixture. Previous studies on Mexican Americans in San Antonio, Texas found some evidence of an association of Native American admixture with obesity and diabetes (Chakraborty et al., 1986; Gardner et al., 1984; Mitchell et al., 1993). However, their findings are not entirely conclusive. Although Chakraborty et al. (1986) found a high rank-order correlation between admixture and prevalence of diabetes, the distribution of individual admixture estimates was similar between cases and controls. Mitchell et al. (1993) found consistently elevated prevalence ratios for both obesity and diabetes comparing Mexican Americans with the most Amerindian admixture to those with the least; however, this was true only for women, and it was unclear whether there was a consistent trend of higher prevalence with greater admixture. No clear association of admixture with diabetes was found in another study of Mexican Americans in Starr County, Texas (Hanis et al., 1986). 
Our findings differ from previous studies that have found greater Native American admixture with lower level of acculturation and of socioeconomic status (SES) in Mexican Americans in San Antonio, Texas (Chakraborty et al., 1986; Mitchell et al., 1993; Relethford et al., 1983). In these studies, residence in a barrio, in a transitional neighborhood, or in an almost exclusively white suburb was used as a surrogate measure for level of acculturation and SES, with barrio residence representing the lowest level of both acculturation and SES. The disparity between our results and results from the San Antonio studies may be attributable to the different methods used to select Mexican American study participants. Whereas the present study recruited a more restricted population of self-identified Mexican Americans, the San Antonio study relied on algorithms based in part on parents' surnames and birthplaces (Hazuda et al., 1986). Clearly, definition and identification of Mexican Americans remain problematic in studies focusing on this ethnic group.

In addition to the availability of information on other covariates to assess potential confounding, the present study also had the advantage of using data on a relatively large, broadbased Mexican American population from the HHANES. Moreover, a primary strength of this study is that all cases of gallbladder disease were diagnosed by using ultrasonography, whereas previous studies of Mexican Americans could identify only clinically diagnosed or symptomatic gallstones; thus, asymptomatic individuals were included in the case population, minimizing misclassification of disease status.

Analyses were conducted without taking into account the complex sampling design of the HHANES, in which multiple individuals could be sampled from one household. However, because the survey chose related individuals from the same household, the results would have been expected to be biased toward finding an association of gallbladder disease with admixture because of the shared environment. Moreover, ignoring the clustering in the sample design would have resulted in an underestimation of variance in our estimates. In our analyses, therefore, taking the sample design into account would have produced 95\% confidence intervals that overlapped even more and would not have altered our conclusions. In addition, although there is potential variation between households with respect to degree of relationship among sampled individuals, we had no reason to expect this degree of relationship to vary by disease status and, therefore, to bias our results.

A limitation of the study is that admixture estimates could be derived for the population only, thus not permitting inferences at the individual level. The study also may be limited by the relatively small number of markers used. However, given the large differences between parental 
allele frequencies for some markers in the GM and KM Ig systems, use of these highly informative and powerful markers should lead to reasonably stable estimates of admixture for this population. Indeed, the GM system has been used successfully to estimate population-level admixture in previous research (Knowler et al., 1988; Williams et al., 1986, 1992).

Future research on admixture-disease associations would benefit from the use of other markers for admixture measurement at an individual level. DNA microsatellites or short tandem repeats (STRs), for example, are potentially useful as markers because the number of repeats at a given locus is so variable (Deka et al. 1995). Moreover, the relative convenience and speed of characterizing large numbers of DNA micro-satellite markers could allow for more precise estimation of admixture for individuals. Future work could also focus on identifying other genetic markers of disease susceptibility. For example, one recent study on the HLA antigen system found a modest association with cholesterol gallstones, specifically when the cases were limited to those with a family history of the disease (Papasteriades et al., 1990). In general, however, attempts to link gallstones with specific genetic markers have not produced striking findings.

In conclusion, this study found no evidence for the hypothesis that greater Native American admixture proportion is associated with higher prevalence of gallbladder disease in Mexican Americans. Possible explanations for the finding that Native American admixture proportions did not differ between cases and noncases remain to be explored. Improving our understanding of the measurement and use of genetic admixture as well as of its limitations will increase its usefulness as an epidemiologic tool. When they are used in genetic epidemiology studies, measurement of admixture have the potential to help explain the apparent excess in prevalence of gallbladder disease in Mexican Americans as well as contribute to current understanding of the distribution of the disease across populations.

\section{LITERATURE CITED}

Chakraborty R, Ferrell RE, Stern MP, Haffner SM, Hazuda HP, and Rosenthal M (1986) Relationship of prevalence of non-insulin-dependent diabetes mellitus to Amerindian admixture in the Mexican Americans of San Antonio, Texas. Genet. Epidemiol. 3:435- 454.

Deka R, Jin L, Shriver MD, Yu LM, deCroo S, Hundrieser J, Bunker CH, Ferrell RE, and Chakraborty R (1995) Population genetics of dinucleotide (dCdA)n(dG-dT)n polymorphisms in world populations. Am. J. Hum. Genet. 56:461-474. 
Diehl AK (1991) Epidemiology and natural history of gallbladder disease. Gastroenterol. Clin. N. Am. 20: 1-19.

Elston RC (1971) The estimation of admixture in racial hybrids. Ann. Hum. Genet. Lond. 35:9-17.

Gardner LI, Stern MP, Haffner SM, Gaskill SP, Hazuda HP, Relethoford JH, and Eifler CW (1984) Prevalence of diabetes in Mexican Americans: Relationship to percent of gene pool derived from native American sources. Diabetes 33:86-92.

Gilat T, Feldman C, Halpern Z, Dan M, and Bar-Meir S (1983) An increased familial frequency of gallstones. Gastroenterology 84:242-246.

Hanis CL, Ferrell RE, Tulloch BR, and Schull WJ (1985) Gallbladder disease epidemiology in Mexican Americans in Starr County, Texas. Am. J. Epidemiol. 122: 820-829.

Hanis CL, Chakraborty R, Ferrell RE, and Schull WJ (1986) Individual admixture estimates: Disease associations and individual risk of diabetes and gallbladder disease among MexicanAmericans in Starr County, Texas. Am. J. Phys. Anthropol. 70:433-441.

Hazuda HP, Comeaux PJ, Stern MP, Haffner SM, Eifler CW, and Rosenthal M (1986) A comparison of three indicators for identifying Mexican Americans in epidemiologic research. Am. J. Epidemiol. 123:96-112.

Jorgensen T (1988) Gallstones in a Danish population: Familial occurrence and social factors. J. Biosoc. Sci. 20:111-120.

Khare M, Everhart JE, and KR Maurer (1995) Association of ethnicity and body mass index (BMI) with gallbladder disease in the United States [abstract]. Am. J. Epidemiol. 141(Suppl.):S69.

Knowler WC, Carraher MJ, Pettitt DJ, and Bennett PH (1984) Epidemiology of cholelithiasis in the Pima Indians. In Capocaccia L, Ricci G, Angelico F, Angelico M, and Attili AF (eds,):

Epidemiology and Prevention of Gallbladder disease. Lancaster, United Kingdom: MTP Press Limited, pp. 15-22.

Knowler WC, Williams RC, Pettitt DJ, and Steinberg AG (1988) Gm G; $^{33,14}$ and type 2 diabetes mellitus: An association in American Indians with genetic admixture. Am. J. Hum. Genet. 43:520-526.

Li, CC (1976) First Course in Population Genetics. Pacific Grove: The Boxwood Press.

Long JC (1991) The genetic structure of admixed populations. Genetics 127:417-428.

Long JC, and Smouse PE (1983) Intertribal gene flow between the Ye'cuana and Yanomama: Genetic analysis of an admixed village. Am. J. Phys. Anthropol. 61:411-422. 
Long JC, Williams RC, McAuley JE, Medis R, Partel R, Tregellas WM, South SF, Rea AE, McCormick SB, and Iwaniec U (1991) Genetic variation in Arizona Mexican Americans: Estimation and interpretation of admixture proportions. Am. J. Phys. Anthropol. 84:141157.

Maurer, KR, Everhart JE, Ezzati TM, Johannes RS, Knowler WC, Larson DL, Sanders R, Shawker TH, and Roth HP (1989) Prevalence of gallbladder disease in Hispanic populations in the United States. Gastroenterology 96:487-492.

Mitchell BD, Williams-Blangero S, Chakraborty R, Valdez R, Hazuda HP, Haffner SM, and Stern MP (1993) A comparison of three methods for assessing Amerindian admixture in Mexican Americans. Ethn. Dis. 3:22-31.

Najar MF, and Rowland M (1987) Anthropometric Reference Data and Prevalence of Overweight: United States, 1976-1980. Vital and Health Statistics, Series 11, No. 238: DHHS publication PHS-87-1688. Washington, D.C.: U.S. Government Printing Office.

National Center for Health Statistics (1985) Plan and operation of the Hispanic Health and Nutrition Examination Survey: 1982-1984 Vital and Health Statistics, Series 1, No. 19. Washington, D.C.: U.S. Government Printing Office.

National Diabetes Data Group (1979) Classification and diagnosis of diabetes mellitus and other categories of glucose intolerance. Diabetes 28:1039-1059.

Papasteriades C, Al-Mahmoud I, Papageorgakis N, St. Romania, Katsas A, Ollier W, and Economidou I (1990) HLA antigens in Greek patients with cholelithiasis. Dis. Markers 8:17-21.

Relethford JH, Stern MP, Gaskill SP, and Hazuda HP (1983) Social class, admixture, and skin color variation in Mexican Americans and Anglo Americans living in San Antonio, Texas. Am. J. Phys. Anthropol. 61:97-102.

Rome Group for Epidemiology and Prevention of Cholelithiasis (GREPCO) (1988) The epidemiology of gallbladder disease in Rome, Italy. Part II. Factors associated with the disease. Hepatology 8:907-913.

Sampliner RE, Bennett PH, Comess LJ, Rose FA, and Burch TA (1970) Gallbladder disease in Pima Indians: Demonstration of high prevalence and early onset by cholecystography. N. Engl. J. Med. 283:1358-1364.

Schanfield MS, and Fudenberg HH (1975) The anthropological usefulness of the IgA allotypic markers. In Watts EW, Johnston FE, and Lasker GW (eds.): Biosocial Interrelations in Population Adaptation. The Hague: Mouton, pp. 105-114. 
Schanfield MS and Polesky HF (1975) Gm and Inv testing. In Polesky HF (ed.): Paternity Testing. Chicago: Division of Educational Media Services, American Society of Clinical Pathologists, pp. 45-54.

Steinberg AG, and Cook CE (1981) The Distribution of the Human Immunoglobulin Allotypes. Oxford: Oxford University Press.

Stern MP, Gonzalez C, Mitchell BD, Villalpando E, Haffner SM, and Hazuda HP (1992) Genetic and environmental determinants of type II diabetes in Mexico City and San Antonio. Diabetes 41:484-492.

van der Linden W (1980) Genetics of cholelithiasis. In Rotter JI, Samloff IM, and Rimoin DL (eds.): Genetics and Heterogeneity of Common Gastrointestinal Disorders. New York: Academic Press, pp. 313-320.

van der Linden W, and Lindelof G (1965) The familial occurrence of gallbladder disease. Acta Genetica 15: 159-164.

van der Linden W, and Simonson N (1973) Familial occurrence of gallbladder disease: Incidence in parents of young patients. Hum. Hered. 23:123-127.

Weiss KM, Ferrell RE, and Hanis CL (1984) A new world syndrome of metabolic diseases with a genetic and evolutionary basis. Yearbk. Phys. Anthropol. 27:153-178.

Wheeler M, Hills LL, and Laby B (1970) Cholelithiasis: A clinical and dietary survey. Gut 11:430437.

Williams RC (1994) Measuring genetic admixture in human populations: The Gila River story. Evol. Anthropol. 3:84-92.

Williams RC, Knowler WC, Pettitt DJ, Long JC, Rokala DA, Polesky HF, Hackenberg RA, Steinberg AG, and Bennett PH (1992) The magnitude and origin of European-American admixture in the Gila River Indian Community of Arizona: A union of genetics and demography. Am. J. Hum. Genet. 51:101-110.

Williams RC, Steinberg AG, Gershowitz H, Bennett PH, Knowler WC, Pettitt DJ, Butler W, Baird R, Dowda-Rea L, Burch TA, Morse HG, and Smith CG (1985) GM allotypes in Native Americans: Evidence for three distinct migrations across the Bering Land Bridge. Am. J. Phys. Anthropol. 66:1-19.

Williams RC, Steinberg AG, Knowler WC, and Pettitt DJ (1986) Gm 3;5,13,14 and stated-admixture: Independent estimates of admixture in American Indians. Am. J. Hum. Genet. 39:409-413.

World Health Organization (1985) Diabetes Mellitus: Report of a WHO Study Group, Technical Report, Series 727. Geneva: World Health Organization, pp. 9-17. 


\begin{tabular}{|c|c|c|c|}
\hline \multicolumn{2}{|c|}{ Allotype } & \multirow[b]{2}{*}{ Agglutinator } & \multirow[b]{2}{*}{ Coat } \\
\hline Alpha-numeric & Numeric & & \\
\hline \multicolumn{4}{|l|}{ G1M } \\
\hline A & 1 & Pec & Rom \\
\hline F & 3 & Sta & Gino \\
\hline $\mathbf{X}$ & 2 & Dren & Rom \\
\hline \multicolumn{4}{|l|}{$\mathrm{G} 1 / 3 \mathrm{M}$} \\
\hline G5 & 28 & Lei & Gem \\
\hline \multicolumn{4}{|l|}{ G2M } \\
\hline$\underset{\text { G3 }}{\mathrm{N}}$ & 23 & $\mathrm{R}-120^{1 \pm 3}$ & Kop $^{4}$ \\
\hline B0 & 11 & $\mathrm{R}-61^{1}$ & Hunt \\
\hline B1 & 5 & Sus & Hunt \\
\hline B3 & 13 & Reams & Hunt \\
\hline B5 & 10 & Stew ${ }^{3}$ & Hunt \\
\hline $\mathrm{C} 3+5$ & 6,24 & Eil & Ada \\
\hline C5 & 24 & Cur & Ada \\
\hline $\mathrm{G}$ & 21 & $\mathrm{R}-68^{1}$ & Gem \\
\hline $\mathbf{S}$ & 15 & $\mathrm{Nad}$ & Sto \\
\hline $\mathrm{T}$ & 16 & Cra & Sto \\
\hline \multicolumn{4}{|l|}{$\mathrm{A} 2 \mathrm{M}$} \\
\hline 1 & 1 & Far & Pren ${ }^{4}$ \\
\hline 2 & 2 & Tay & $\mathrm{Bapt}^{4}$ \\
\hline \multicolumn{4}{|l|}{ KM } \\
\hline 1 & 1 & Grob & Bar \\
\hline 3 & 3 & $\mathrm{Nee}^{3}$ & Gino \\
\hline
\end{tabular}

TABLE 2. Distribution for GM phenotypes, six haplotype model ${ }^{1}$

\begin{tabular}{|c|c|c|c|}
\hline Phenotype & Probable gen otype(s) & Number & Frequency \\
\hline $\begin{array}{l}\text { A G } \\
\text { A,X G } \\
\text { A,F B0,G } \\
\text { A B0,G } \\
\text { A B0,C5,G } \\
\text { A B0,G,S or A B0,G,T } \\
\text { A,F,X B0,G } \\
\text { A,X B0,G } \\
\text { A,X B0,C5,G } \\
\text { A,X B0,G,S or A,X B0,G,T } \\
\text { F B0 } \\
\text { A,F B0 } \\
\text { A,F B0,C5 } \\
\text { A,F B0,S or A,F B0,T } \\
\text { A B0 } \\
\text { A B0,C5 } \\
\text { A B0,S or A B0,T } \\
\text { A B0,C5,S or A B0,C5,T } \\
\text { Tota1 }\end{array}$ & 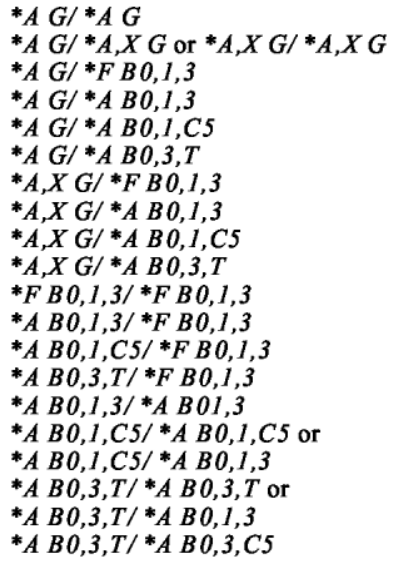 & $\begin{array}{r}268 \\
98 \\
360 \\
31 \\
3 \\
19 \\
110 \\
7 \\
1 \\
4 \\
162 \\
41 \\
5 \\
7 \\
2 \\
\\
1 \\
\\
1 \\
0 \\
1,120\end{array}$ & $\begin{array}{l}0.239 \\
0.088 \\
0.321 \\
0.028 \\
0.003 \\
0.017 \\
0.098 \\
0.006 \\
0.001 \\
0.004 \\
0.145 \\
0.037 \\
0.004 \\
0.006 \\
0.002 \\
\\
0.001\end{array}$ \\
\hline
\end{tabular}

${ }^{1}$ The six GM haplotypes assumed to be segregating in the population were ${ }^{*} A G,{ }^{*} A, X G,{ }^{*} A B 0,1,3,{ }^{*} A B 0,3, T,{ }^{*} A B 0,1, C 5$, and ${ }^{*} F B 0,1,3$. 


\begin{tabular}{|c|c|c|}
\hline Phenotype & Proposed genotype & Number \\
\hline $\begin{array}{l}\text { A,F B1,C5,G } \\
\text { F B1,S } \\
\text { A,F B1,G,S } \\
\text { A G,T } \\
\text { F B1,C5,S } \\
\text { A,F B1,C5,G,S } \\
\text { A,X G,T } \\
\text { F B1,G } \\
\text { A G,S } \\
\text { A,F G } \\
\text { A C5,G } \\
\text { F B1,C5,G,S } \\
\text { Tota1 }\end{array}$ & $\begin{array}{l}{ }^{*} A G /{ }^{*} F B 0,1,3, C 5 \\
{ }^{*} F B O, 1,3 /{ }^{*} F B 0,1,3, S \\
{ }^{*} A G /{ }^{*} F B 0,1,3, S \\
{ }^{*} A G /{ }^{*} A G, T \\
{ }^{*} F B 0,1,3 /{ }^{*} F B 0,1,3, C 5, S \\
{ }^{*} A G /{ }^{*} F B 0,1,3, C 5, S \\
{ }^{*} A, X G /{ }^{*} A G, T \\
{ }^{*} F G /{ }^{*} F B 0,1,3 \\
{ }^{*} A G /{ }^{*} A G, S \\
{ }^{*} A G /{ }^{*} F G \\
{ }^{*} A G /{ }^{*} A C 5, G \\
{ }^{*} F G /{ }^{*} F B 0,1,3, C 5, S\end{array}$ & $\begin{array}{r}1 \\
2 \\
3 \\
3 \\
4 \\
4 \\
1 \\
1 \\
1 \\
4 \\
1 \\
1 \\
26\end{array}$ \\
\hline
\end{tabular}

TABLE 4. Distribution for KM phenotypes

\begin{tabular}{llrc}
\hline Phenotype & Probable genotype(s) & Number & Frequency \\
\hline Km 1+ & $K m^{*} 1 / K m^{*} 1$ or & 412 & 0.366 \\
& $K m^{*} 1 / K m * 3$ & & \\
Km 1- & $K m * 3 / K m * 3$ & 715 & 0.634 \\
Total & & 1,127 & \\
\hline
\end{tabular}

TABLE 5. Haplotype and allele frequencies for GM and $K M$

\begin{tabular}{|c|c|c|c|c|}
\hline \multirow[b]{2}{*}{$\begin{array}{c}\text { Haplotype/ } \\
\text { Allele }\end{array}$} & \multicolumn{3}{|c|}{ Parental population ${ }^{1}$} & \multirow{2}{*}{$\begin{array}{c}\text { HHANES } \\
\text { Mexican American } \\
(95 \% \mathrm{CI})\end{array}$} \\
\hline & European & $\begin{array}{c}\text { Native } \\
\text { American }\end{array}$ & African & \\
\hline${ }^{*} A G$ & 0.209 & 0.904 & 0.001 & $0.463(0.441,0.485)$ \\
\hline$* A, X G$ & 0.089 & 0.054 & 0.000 & $0.103(0.089,0.117)$ \\
\hline$* A B 0,1,3$ & 0.014 & 0.000 & 0.780 & $0.038(0.030,0.046)$ \\
\hline${ }^{*} A B 0,1, C 5$ & 0.000 & 0.000 & 0.199 & $0.004(0.002,0.006)$ \\
\hline${ }^{*} A B 0,3, T$ & 0.000 & 0.029 & 0.020 & $0.014(0.010,0.018)$ \\
\hline${ }^{*} F B 0,1,3$ & 0.688 & 0.013 & 0.000 & $0.378(0.358,0.398)$ \\
\hline$K m * 1$ & 0.082 & 0.400 & 0.359 & $0.204(0.186,0.222)$ \\
\hline$K m * 3$ & 0.918 & 0.600 & 0.641 & $0.796(0.779,0.814)$ \\
\hline
\end{tabular}

${ }^{1}$ Allele frequencies for parental populations were taken from published reports (Williams et al., 1985; Steinberg and Cook, 1981). HHANES, H ispanic Health and Nutrition Examination Survey; 95\% CI, 95\% con ®dence interval.

TABLE 6. Characteristics of study sample

\begin{tabular}{|c|c|c|c|}
\hline Covariate & $\begin{array}{c}\text { Total } \\
(\mathrm{n}=1145)\end{array}$ & $\begin{array}{c}\text { Gallbladder } \\
\text { disease } \\
(n=156)\end{array}$ & $\begin{array}{c}\text { No } \\
\text { gallbla dder } \\
\text { disease } \\
(\mathrm{n}=989)\end{array}$ \\
\hline \multicolumn{4}{|l|}{ Age, years } \\
\hline $\begin{array}{l}\text { (mean, SD) } \\
\text { Age group }(\%)\end{array}$ & $40.5(14.2)$ & $47.8(14.5)$ & 39.4 (13.9) \\
\hline $20 \pm 39$ & 54.1 & 32.0 & 57.6 \\
\hline $40 \pm 74$ & 45.9 & 68.0 & 42.4 \\
\hline Female (\%) & 52.8 & 79.5 & 48.6 \\
\hline \multicolumn{4}{|l|}{$\begin{array}{l}\text { Body mass } \\
\text { index, } \mathrm{kg} / \mathrm{m}^{2}\end{array}$} \\
\hline (mean, sd) & $26.6(4.9)$ & $28.0(5.0)$ & $26.3(4.8)$ \\
\hline Overweight (\%) & 36.2 & 50.6 & 34.0 \\
\hline Diabetic (\%) & 9.0 & 15.4 & 8.0 \\
\hline $\begin{array}{l}\text { Acculturation } \\
\text { score } \\
\text { (mean, sd) }\end{array}$ & $2.6(1.3)$ & $2.5(1.0)$ & $2.5(1.0)$ \\
\hline
\end{tabular}


TABLE 7. Estimates of genetic adm ixture and $95 \%$ con $\mathbb{B}$ dence intervals

\begin{tabular}{lccr}
\hline \multicolumn{1}{c}{ Status } & European & Native American & African \\
\hline Total & $0.575(0.491,0.659)$ & $0.390(0.307,0.473)$ & $0.035(0.007,0.063)$ \\
Gallbladder disease & $0.589(0.486,0.691)$ & $0.359(0.258,0.460)$ & $0.053(0.013,0.092)$ \\
No gallbladder disease & $0.573(0.495,0.651)$ & $0.396(0.319,0.473)$ & $0.031(0.006,0.055)$ \\
\hline
\end{tabular}

TABLE 8. Estimates of genetic adm ixture and $95 \%$ con $₫$ dence intervals by levels of covariates

\begin{tabular}{llll}
\hline \multicolumn{1}{c}{ Covariate } & European & Native American & African \\
\hline Age (years) & & & \\
$\quad 20 \pm 39$ & $0.56(0.49,0.64)$ & $0.40(0.33,0.47)$ & $0.03(0.01,0.06)$ \\
$\quad 40 \pm 74$ & $0.59(0.49,0.68)$ & $0.38(0.28,0.47)$ & $0.03(0.002,0.07)$ \\
Sex & & & \\
$\quad$ Female & $0.58(0.50,0.66)$ & $0.38(0.30,0.46)$ & $0.04(0.01,0.07)$ \\
$\quad$ Male & $0.57(0.49,0.65)$ & $0.41(0.33,0.49)$ & $0.02(0,0.05)$ \\
Body mass index & $0.57(0.51,0.63)$ & $0.39(0.33,0.45)$ & $0.04(0.02,0.06)$ \\
$\quad$ Overweight & $0.58(0.46,0.70)$ & $0.39(0.27,0.51)$ & $0.03(0,0.07)$ \\
$\quad$ Not overweight & $0.55(0.34,0.76)$ & $0.42(0.21,0.62)$ & $0.03(0,0.10)$ \\
Diabetes status & $0.58(0.51,0.65)$ & $0.39(0.32,0.46)$ & $0.03(0.01,0.06)$ \\
$\quad$ Diabetic & & & \\
$\quad$ Nondiabetic & $0.59(0.49,0.69)$ & $0.37(0.28,0.47)$ & $0.03(0.002,0.07)$ \\
Acculturation (tertiles) & $0.57(0.59,0.65)$ & $0.40(0.32,0.48)$ & $0.04(0.01,0.06)$ \\
$\quad$ Low & $0.57(0.50,0.64)$ & $0.40(0.33,0.47)$ & $0.03(0.01,0.05)$ \\
$\quad$ Intermediate & & & \\
$\quad$ High & & & \\
\hline
\end{tabular}

